\title{
Characterization of Aluminum Nitride from a Precursor Poly (isopropyliminoalane)
}

\author{
Yasuo SAITO*, Seiichi KOYAMA*, Yoshiyuki SUGAHARA* and Kazuyuki KURODA*,** \\ *Department of Applied Chemistry, School of Science and Engineering, Waseda University, 4-1, Ohkubo 3 chome, Shinjuku-ku, Tokyo 169 \\ ** Kagami Memorial Laboratory for Materials Science and Technology, Waseda University, \\ 8-26, Nishiwaseda 2 chome, Shinjuku-ku, Tokyo 169
}

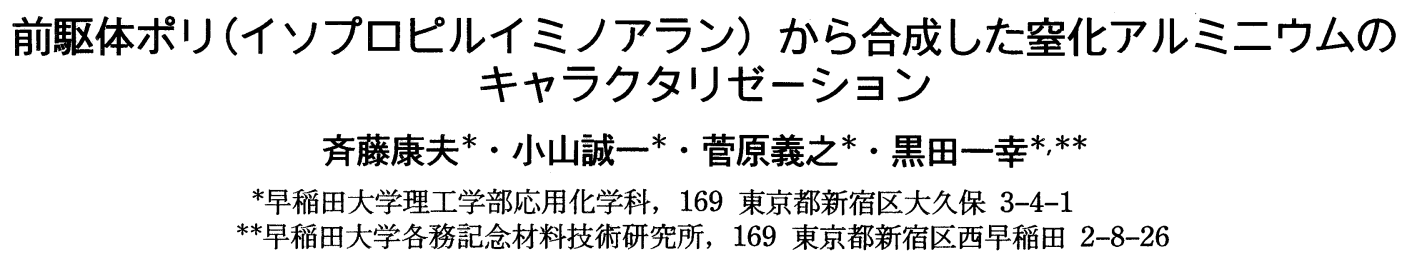

\begin{abstract}
Aluminum nitride (AIN) was prepared by pyrolysis of poly(isopropyliminoalane) under Ar and $\mathrm{NH}_{3} / \mathrm{N}_{2}$ atmospheres. $\mathrm{X}$-ray powder diffraction analysis revealed that the only crystalline phase was AlN, whose lattice constants showed that possible amounts of carbon and oxygen in the lattice should be very small. Chemical analyses showed the presence of carbon only in the product pyrolyzed in Ar; almost all carbon was removed by pyrolysis in $\mathbf{N H}_{3} / \mathbf{N}_{2}$. The ceramic yield for two-step pyrolysis in $\mathbf{A r}$ $\left(1000^{\circ} \mathrm{C}\right.$ for $2 \mathrm{~h}, 1^{\circ} 600^{\circ} \mathrm{C}$ for $\left.2 \mathrm{~h}\right)$ was $32 \%$, while that for pyrolysis in $\mathrm{NH}_{3} / \mathrm{N}_{2}\left(600^{\circ} \mathrm{C}\right.$ for $2 \mathrm{~h}$ in $\mathrm{NH}_{3}, 1_{350}^{\circ} \mathrm{C}$ for $8 \mathrm{~h}$ in $\mathrm{N}_{2}$ ) was $47 \%$.

[Received August 3, 1995; Accepted November 13, 1995]
\end{abstract}

Key-words : Aluminum nitride, Precursor, Poly(isopropyliminoalane), Pyrolysis

1. Introduction

Aluminum nitride (AlN) has attracted increasing attention in electronics applications, since it exhibits high thermal conductivity. AlN has been prepared by several methods including (1) carbothermal reduction of $\mathrm{Al}_{2} \mathrm{O}_{3}$ under nitrogen atmosphere, (2) nitridation of aluminum metal, and (3) vapor-phase reactions such as a chemical vapor deposition process. Vapor-phase reactions are suitable for AlN film preparation, but other methods can be applied only for powder preparation. Hence an alternative preparative method should be developed for application of AlN to films and fibers.

Pyrolytic routes from preceramic inorganic and organometallic polymers to non-oxide ceramics show promise in applications to films and fibers via liquidphase syntheses. ${ }^{1)-3)}$ Since the discovery of the Yajima process, ${ }^{4}$ i.e., the conversion of poly (carbosilane) to silicon carbide ( $\mathrm{SiC}$ ), extensive work has been reported on the preparation of $\mathrm{SiC}$, silicon nitride $\left(\mathrm{Si}_{3} \mathrm{~N}_{4}\right)$, and boron nitride (BN) ${ }^{1), 2)} \mathrm{AlN}$ can also be prepared via pyrolysis, and preceramic polymers for AlN synthesis have mainly been prepared via condensation reactions between an aluminum source (trialkyl aluminum $\left(\mathrm{R}_{3} \mathrm{Al}\right)^{5)-13)}$ or $\mathrm{AlH}_{3}{ }^{14)-18}$ ) (including its adduct and lithium aluminum hydride)) and a nitrogen source $\left(\mathrm{NH}_{3}\right.$ and organic amines). Furthermore, alternative electrochemical syntheses have recently been developed. ${ }^{19)-24)}$

Among various compounds possessing Al-N bonds, cage-type compounds called poly(alkyliminoalane) have been prepared. ${ }^{25)}$ We have shown that poly (isopropyliminoalane), which mainly consists of a cage-type hexamer $\left(\mathrm{HAlNPr}^{i}\right)_{6}$, can be successfully converted into AlN by pyrolysis in $\mathrm{Ar},{ }^{26)}$ and have clarified the pyrolysis process of poly(isopropyliminoalane) mainly by analyzing the gases evolved.27)

We describe here the characterization of products obtained by pyrolysis under both inert (Ar) and reactive $\left(\mathrm{NH}_{3} / \mathrm{N}_{2}\right)$ atmospheres. Since $\mathrm{NH}_{3}$ atmosphere has commonly been used for pyrolysis routes for nitride ceramics, we report our results on the pyrolysis in $\mathrm{NH}_{3} / \mathrm{N}_{2}$. Moreover, since our characterization of pyrolysis products was insufficient in the previous reports, we here report on the detailed characterization of pyrolyzed products by X-ray powder diffraction analysis (XRD) and chemical analysis.

\section{Experimental}

All the procedures were performed under a protective nitrogen atmosphere using the standard Schlenk technique. ${ }^{28)}$ Poly(isopropyliminoalane) was prepared according to the following reaction. ${ }^{29)}$

$$
\begin{aligned}
& n \mathrm{LiAlH}_{4}+n \mathrm{Pr}^{i} \mathrm{NH}_{2} \stackrel{n \text {-heptane }}{\longrightarrow} \\
& \quad\left(\mathrm{HAlNPr}^{i}\right)_{n}+n \mathrm{LiH}+2 n \mathrm{H}_{2}
\end{aligned}
$$

The precursor was soluble in common organic solvents. Experimental details and spectroscopic characteristics have been described elsewhere. ${ }^{26)}$

The precursor was pyrolyzed using a tube furnace. For pyrolysis under Ar atmosphere, the precursor in a BN boat was placed in a quartz tube filled with Ar. Then the precursor was pyrolyzed at $1000^{\circ} \mathrm{C}$ for $2 \mathrm{~h}$ 
under $\operatorname{Ar}$ flow $(100 \mathrm{~mL} / \mathrm{min})$. The product pyrolyzed at $1000^{\circ} \mathrm{C}$ was further heated at $1600^{\circ} \mathrm{C}$ for $2 \mathrm{~h}$ under $\mathrm{Ar}$ flow $(100 \mathrm{~mL} / \mathrm{min})$ in an $\mathrm{Al}_{2} \mathrm{O}_{3}$ tube. For pyrolysis in $\mathrm{NH}_{3} / \mathrm{N}_{2}$, the precursor in a $\mathrm{BN}$ boat was placed in an $\mathrm{Al}_{2} \mathrm{O}_{3}$ tube filled with $\mathrm{NH}_{3}$, pyrolyzed at $600^{\circ} \mathrm{C}$ for $2 \mathrm{~h}$ under $\mathrm{NH}_{3}$ flow $(30 \mathrm{~mL} / \mathrm{min})$, and cooled to room temperature. For the subsequent pyrolysis at high temperature, the gas was switched to $\mathrm{N}_{2}$, since $\mathrm{NH}_{3}$ undergoes a certain amount of dissociation into $\mathrm{N}_{2}$ and $\mathrm{H}_{2}$ above $650^{\circ} \mathrm{C} ; 30$ ),31) the $\mathrm{Al}_{2} \mathrm{O}_{3}$ tube was thoroughly purged with $\mathrm{N}_{2}$, and the product was heated under $\mathrm{N}_{2}$ flow $(30 \mathrm{~mL} / \mathrm{min})$ at $1350^{\circ} \mathrm{C}$ for $8 \mathrm{~h}$. The heating and cooling rate was $5^{\circ} \mathrm{C} /$ min for all pyrolyses.

The crystalline products were identified by X-ray powder diffraction (XRD) using Mac Science MXP ${ }^{3}$ diffractometer (monochromated $\mathrm{Cu} \mathrm{K} \alpha$ radiation). Lattice parameters of pyrolyzed products were estimated from XRD data by the non-linear least squares method. The amount of carbon was determined using Horiba Ltd., EMIA-520SP, and those of nitrogen and oxygen were estimated using Horiba Ltd, EMGA-2800.

\section{Results and discussion}

After pyrolysis in Ar, a black solid was obtained, whereas a white powder formed by pyrolysis in $\mathrm{NH}_{3} / \mathrm{N}_{2}$. The chemical compositions of the products are listed in Table 1. Both products mainly contain aluminum and nitrogen. Upon pyrolysis in Ar, a considerable amount of carbon also remains in the product. Thus, some isopropyl groups in the precursor are converted into carbonaceous materials during pyrolysis in Ar. In contrast, most of the carbon is removed during pyrolysis in $\mathrm{NH}_{3} / \mathrm{N}_{2}$. Removal of carbon by pyrolysis in $\mathrm{NH}_{3}$ has been reported for various precursors including AlN precursors, 8),12),13),16),23),24) poly (carbosilane), 30),32)-34) poly(silazane), ${ }^{32), 35), 36)}$ and polysilane. ${ }^{31), 32), 37)}$ A possible explanation for the removal of carbon is an amine-exchange reaction, ${ }^{9)}$ where an amido group $\left(=\mathrm{NH}_{2}\right)$ displaces a $\operatorname{Pr}^{i} \mathrm{~N}=$ group in the precursor and isopropyl amine is liberated.

$$
=\mathrm{NPr}^{i}+\mathrm{NH}_{3} \longrightarrow=\mathrm{NH}+\mathrm{Pr}^{i} \mathrm{NH}_{2}
$$

It should also be noted that certain amounts of oxygen are detected. Since N/Al molar ratios are less than unity, oxygen should be bound to aluminum. The presence of oxygen should be ascribed to the hydrolysis of the surface of AlN due to the exposure to air after pyrolysis and/or the high sensitivity of

Table 1. Compositional Characteristics of the Products Pyrolyzed in $\mathrm{Ar}$ (at $1000^{\circ} \mathrm{C}$ for $2 \mathrm{~h}$ and Subsequently at $1600^{\circ} \mathrm{C}$ for $2 \mathrm{~h}$ ) and $\mathrm{NH}_{3} / \mathrm{N}_{2}$ (at $600^{\circ} \mathrm{C}$ for $2 \mathrm{~h}$ in $\mathrm{NH}_{3}$ and Subsequently at $1350^{\circ} \mathrm{C}$ for $8 \mathrm{~h}$ in $\mathrm{N}_{2}$ )

\begin{tabular}{ccccccc}
\hline Pyrolysis & \multicolumn{5}{c}{ Elemental Analysis / mass\% } & Compositional \\
\cline { 2 - 6 } Atmosphere & $\mathrm{Al}$ & $\mathrm{N}$ & $\mathrm{O}$ & $\mathrm{C}$ & Total & Formula \\
\hline $\mathrm{Ar}$ & 45.2 & 20.8 & 5.5 & 20.6 & 92.1 & $\mathrm{AlN}_{0.89} \mathrm{O}_{0.20} \mathrm{C}_{1.03}$ \\
$\mathrm{NH}_{3} / \mathrm{N}_{2}$ & 58.1 & 28.9 & 7.5 & 0.5 & 95.0 & AlN $_{0.96} \mathrm{O}_{0.22} \mathrm{C}_{0.02}$ \\
\hline
\end{tabular}

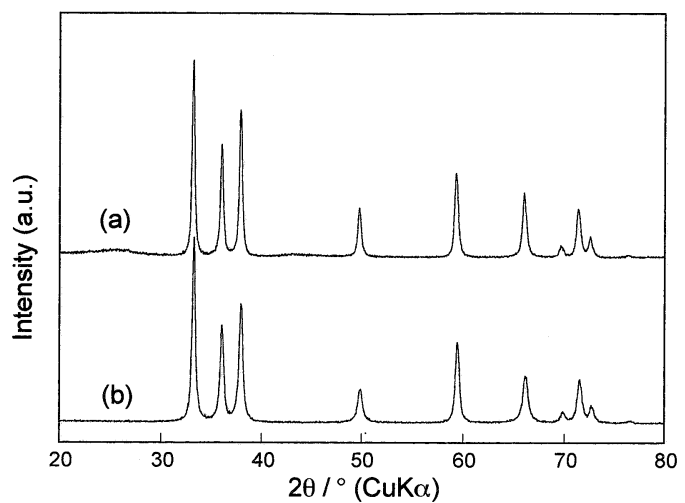

Fig. 1. XRD patterns of the products pyrolyzed (a) in $\mathrm{Ar}$ (at $1000^{\circ} \mathrm{C}$ for $2 \mathrm{~h}$ and subsequently at $1600^{\circ} \mathrm{C}$ for $2 \mathrm{~h}$ ) and (b) in $\mathrm{NH}_{3} / \mathrm{N}_{2}$ (at $600^{\circ} \mathrm{C}$ for $2 \mathrm{~h}$ in $\mathrm{NH}_{3}$ and subsequently at $1350^{\circ} \mathrm{C}$ for $8 \mathrm{~h}$ in $\mathrm{N}_{2}$ ).

the precursor to moisture.

Figure 1 shows the XRD patterns of the products. Irrespective of the pyrolysis atmosphere, XRD patterns correspond to single-phase $2 \mathrm{H}$-wurtzite-type compounds. The product pyrolyzed at $1000^{\circ} \mathrm{C}$ in $\mathrm{Ar}$ is amorphous, so that pyrolysis at $1600^{\circ} \mathrm{C}$ is required for crystallization. ${ }^{26)}$ Similarly, since the precursor pyrolyzed in $\mathrm{NH}_{3}$ at $600^{\circ} \mathrm{C}$ for $2 \mathrm{~h}$ is amorphous, pyrolysis at $1350^{\circ} \mathrm{C}$ causes crystallization of AlN. Thus, relatively high pyrolysis temperatures are necessary for crystallization.

Lattice parameters of the products are refined as follows; $a=0.311(5) \mathrm{nm}$ and $c=0.498(5) \mathrm{nm}$ for the product pyrolyzed in $\mathrm{Ar}$, and $a=0.310(9) \mathrm{nm}$ and $c=0.497(6) \mathrm{nm}$ for the product pyrolyzed in $\mathrm{NH}_{3} / \mathrm{N}_{2}$. These values are well consistent with those reported for AlN ( $a=0.310-0.3114 \mathrm{~nm}, c=0.496-$ $0.4986 \mathrm{~nm}){ }^{38)} \mathrm{Al}_{2} \mathrm{OC}$ is another Al-containing isostructural compound with slightly larger lattice parameters $\left.(a=0.319 \mathrm{~nm}, c=0.509 \mathrm{~nm}),{ }^{39}\right)$ and is known to form solid solutions with AlN. ${ }^{40)}$ According to the observed lattice parameters, however, we conclude that a possible amount of $\mathrm{Al}_{2} \mathrm{OC}$ present in $2 \mathrm{H}$-wurtzite-type compounds is very small. Hence, carbon detected in the product pyrolyzed in $\mathrm{Ar}$ should be present as an amorphous phase. The observed lattice parameters also suggest that the amount of oxygen present in the AlN lattice is small. ${ }^{40)}$ Since no crystalline oxynitride or oxides are identified, oxygen should be present as an amorphous phase.

The ceramic yield for pyrolysis in Ar was 32\%. According to this yield and chemical analysis data listed in Table 1, the amount of aluminum lost during pyrolysis in Ar can be estimated as $\sim 55 \%$ of aluminum in the precursor. This is consistent with our thermogravimetric-mass spectroscopic (TG-MS) results, which revealed that a considerable amount of aluminum was lost in the temperature range from 240 to $320^{\circ} \mathrm{C} .{ }^{27)} \mathrm{A}$ similar estimation for the same precursor was reported on the basis of the TG 
results (yield $39 \%$, up to $900^{\circ} \mathrm{C}$ ) and the carbon content; about $35 \%$ of aluminum was lost up to $900^{\circ} \mathrm{C} .{ }^{27)}$ This appears to be consistent with the ceramic yield in the present study for $1000^{\circ} \mathrm{C}$ pyrolysis (40\%). Thus, an additional loss $(8 \%)$ observed during the second pyrolysis should correspond to the loss of $\sim 20 \%$ of aluminum. In the present study, we pyrolyzed the precursor via two steps. Hence, a certain amount of oxygen appears to be introduced in the product pyrolyzed at $1000^{\circ} \mathrm{C}$, and additional aluminum may be lost via carbothermal reduction as a vapor-phase intermediate such as $\mathrm{Al}_{2} \mathrm{O} .{ }^{41}$ ) This is supported by the fact that $20 \%$ of aluminum in the precursor corresponds to $\sim 6$ mass $\%$ of the precursor, which is slightly lower than the observed value.

The ceramic yield for pyrolysis in $\mathrm{NH}_{3} / \mathrm{N}_{2}$ is $47 \%$, which is similar to the theoretical one $(48.2 \%)$. Based on the calculation, which is similar to that described above, only $14 \%$ of aluminum is lost during pyrolysis in $\mathrm{NH}_{3} / \mathrm{N}_{2}$. Thus the relatively high ceramic yield appears to be attributable to the crosslinked structure of the product after the removal of carbon by $\mathrm{NH}_{3}$.

\section{Conclusions}

We have shown the characteristics of the products prepared by the pyrolysis of poly (isopropyliminoalane) under $\mathrm{Ar}$ and $\mathrm{NH}_{3} / \mathrm{N}_{2}$ atmospheres. Besides aluminum and nitrogen, both the products pyrolyzed under $\mathrm{Ar}$ and $\mathrm{NH}_{3} / \mathrm{N}_{2}$ atmospheres contain a certain amount of oxygen. A large amount of carbon is also present in the product after the pyrolysis in Ar. The only crystalline phase is the $2 \mathrm{H}$-wurtzite-type compound and its lattice parameters are well consistent with those of AlN; 2H-wurtzite-type compound possibly contains a very small amounts of oxygen and carbon only. Compared with the pyrolysis in $\mathrm{Ar}$, a much smaller amount of aluminum is lost during the pyrolysis in $\mathrm{NH}_{3} / \mathrm{N}_{2}$, which leads to the relatively high ceramic yield $(47 \%)$.

Acknowledgments This work was financially supported by the Grant-in-Aid for Encouragement of Young Scientists from the Ministry of Education, Science and Culture (No. 03750584), the Kawakami Memorial Foundation, and Waseda University (Special Research Project).

\section{References}

1) R. W. Rice, Am. Ceram. Soc. Bull., 62, 889-92 (1983).

2) G. Pouskouleli, Ceram. Int., 15, 213-29 (1989).

3) B. Liao, Y. Li and Y. Lu, J. Mater. Chem., 3, 117-27 (1993).

4) S. Yajima, J. Hayashi and M. Omori, Chem. Lett., 9, 931-34 (1975).

5) L. V. Interrante, L. E. Carpenter, II, C. Whitmarsh, W. Lee, M. Gorbouskas and G. A. Slack, Mater. Res. Soc. Symp. Proc., 73, (1986) pp. 359-66.

6) R. T. Baker, J. D. Bolt, G. S. Reddy, D. C. Roe, R. H. Staley, F. N. Tebbe and A. J. Vega, Mater. Res. Soc. Symp. Proc., 121, (1988) pp. 471-76.

7) F. N. Tebbe, J. D. Bolt, R. J. Young, Jr., O. R. Van Buskirk, W. Mahler, G. S. Reddy and U. Chowdhry, "Advances in Ceramics”, Vol. 26, Am. Ceram. Soc. (1989) pp. 63-68.
8) J. D. Bolt and F. N. Tebbe, "Advances in Ceramics", Vol. 26, Am. Ceram. Soc. (1989) pp. 69-76.

9) Z. Jiang and L. V. Interrante, Chem. Mater., 2, 439-46 (1990).

10) Z. Jiang, L. V. Interrante, D. Kwon, F. S. Tham and R. Kullnig, Inorg. Chem., 30, 995-1000 (1991).

11) Z. Jiang, L. V. Interrante, D. Kwon, F. S. Tham and R. Kullnig, Inorg. Chem., 31, 4815-22 (1992).

12) J. A. Jensen, Mater. Res. Soc. Symp. Proc., 271 (1992) pp. 845-50.

13) F. C. Sauls, W. J. Hurley, Jr., L. V. Interrante, P. S. Marchetti and G. E. Maciel, Chem. Mater., 7, 1361-68 (1995).

14) L. Maya, Adv. Ceram. Mater., 1, 150-53 (1986).

15) A. Ochi, H. K. Bowen and W. E. Rhine, Mater. Res. Soc. Symp. Proc., 121 (1988) pp. 663-66.

16) J. F. Janik and R. T. Paine, J. Organomet. Chem., 449, 3944 (1993).

17) P. R. Coffman, W. T. Petuskey and S. K. Dey, Mater. Res. Soc. Symp. Proc., 180 (1990) pp. 709-14.

18) W. Rockensüß and H. W. Roesky, Adv. Mater., 5, 443-45 (1993)

19) C. B. Ross, T. Wade and R. M. Crooks, Chem. Mater., 3, 768-71 (1991).

20) T. Wade, J. Park, G. Garza, C. B. Ross, D. M. Smith and R. M. Crooks, J. Am. Chem. Soc., 114, 9457-64 (1992).

21) T. Wade, J. Park, G. Garza, C. B. Ross, D. M. Smith and R. M. Crooks, Mater. Res. Soc. Symp. Proc., 271 (1992) pp. 857-68.

22) M. M. Seibold and C. Rüssel, Mater. Res. Soc. Symp. Proc., 121 (1988) pp. 477-82.

23) M. M. Seibold and C. Rüssel, J. Am. Ceram. Soc., 72, 150305 (1989).

24) I. Teusel and C. Rüssel, J. Mater. Sci., 27, 133-38 (1992).

25) M. Cesari and S. Cucinella, "The Chemistry of Inorganic Homo- and Heterocycles", Ed. by I. Haiduc and D.B. Sowerby, Academic Press (1987) pp.167-90.

26) Y. Sugahara, T. Onuma, O. Tanegashima, K. Kuroda and C. Kato, J. Ceram. Soc. Japan, 100, 101-03 (1992).

27) Y. Saito, Y. Sugahara and K. Kuroda, submitted to J. Am. Ceram. Soc.

28) D. F. Shriver and M. A. Drezdzon, "The Manipulation of Air-Sensitive Compounds", 2nd ed., Wiley-Interscience, NY (1986).

29) S. Cucinella, G. Dozzi, A. Mazzei and T. Salvatori, J. Organomet. Chem., 90, 257-67 (1975).

30) R. J. P. Corriu, D. Leclercq, P. H. Mutin and A. Vioux, Chem. Mater., 4, 711-16 (1992).

31) W. R. Schmidt, P. S. Marchetti, L. V. Interrante, W. J. Hurley, Jr., R. H. Lewis, R. H. Doremus and G. E. Maciel, Chem. Mater., 4, 937-47 (1992).

32) G. T. Burns and G. Chandra, J. Am. Ceram. Soc., 72, 333-37 (1989).

33) T. Taki, M. Inui, K. Okamura and M. Sato, J. Mater. Sci. Lett., 8, 1119-21 (1989).

34) K. Okamura, M. Sato and Y. Hasegawa, Ceram. Int., 13, 55-61 (1987).

35) Y. F. Yu and T. I. Mah, Mater. Res. Soc. Symp. Proc., 73 (1986) pp. 559-64.

36) N. S. C. K. Yive, R. J. P. Corriu, D. Leclercq, P. H. Mutin and A. Vioux, Chem. Mater., 4, 1263-71 (1992).

37) W. R. Schmidt, V. Sukumar, W. J. Hurley, Jr., R. Garcia, R. H. Doremus and L. V. Interrante, J. Am. Ceram. Soc., 73, 2412-18 (1990).

38) K. M. Taylor and C. Lenie, J. Electrochem. Soc., 107, 308-14 (1960).

39) I. B. Cutler, P. D. Miller, W. Rafaniello, H. K. Park, D. P. Thompson and K. H. Jack, Nature, 275, 434-35 (1978).

40) G. A. Slack, J. Phys. Chem. Solids, 34, 321-35 (1973).

41) H.-K. Chen, C.-I Lin and C. Lee, J. Am. Ceram. Soc., 77, 1753-56 (1994). 